\title{
Preparation of Activated Carbons from Sisal Fibers as Anode Materials for Lithium Ion Batteries
}

\author{
Rui Du ${ }^{1,2}$, Zhangfa Tong ${ }^{1}$, Chun Wei ${ }^{1,2}$, Aimiao Qin ${ }^{2,3, *}$ \\ ${ }^{1}$ School of Chemistry and Chemical Engineering, Guangxi University, Nanning 530001, PR China \\ ${ }^{2}$ Guangxi Scientific Experiment Center of Mining, Metallurgy and Environment, Key Laboratory of \\ New Processing Technology for Nonferrous Metals and Materials, Ministry of Education, College of \\ Materials Science and Engineering, Guilin University of Technology, Guilin 541004, PR China. \\ ${ }^{3}$ Guangxi Experiment Center of Information Science, Guilin 541004, PR China. \\ *E-mail: 317881264@qq.com
}

doi: $10.20964 / 2016.10 .19$

Received: 2 July 2016 / Accepted: 11 August 2016 / Published: 6 September 2016

\begin{abstract}
Activated carbons have been prepared by pyrolysis of sisal fibers at different temperatures and hydrothermal treatment after pyrolysis. The obtained sisal fiber activated carbons (SFACs) are subjected to X-ray powder diffraction (XRD), BET-surface area, SEM, Cyclic voltammetry, Chargedischarge studies and Electrochemical impedance spectroscopy studies. The structures of the SFACs have been changed with the increased pyrolysis temperature and the hydrothermal treatment. The SFACs pyrolyzed at $900^{\circ} \mathrm{C}$ with hydrothermal treatment have more micropores than others. The electrochemical tests show that the SFACs pyrolyzed at $900^{\circ} \mathrm{C}$ with hydrothermal treatment offer an extraordinarily high initial capacity of $998 \mathrm{mAhg}^{-1}$ and the charge-transfer resistance of $90 \Omega$. The work highlights the potential to utilize sisal fibers to produce anode materials for lithium ion batteries.
\end{abstract}

Keywords: Sisal fiber, activated carbon, pyrolysis, hydrothermal treatment, lithium ion battery

\section{$\underline{\text { FULL TEXT }}$}

(C) 2016 The Authors. Published by ESG (www.electrochemsci.org). This article is an open access article distributed under the terms and conditions of the Creative Commons Attribution license (http://creativecommons.org/licenses/by/4.0/). 